\title{
Research on Decoration and Design of B2C Transactional Shop Based on User Experience
}

\author{
Ying Zhang ${ }^{1, \text { a }}$ \\ ${ }^{1}$ Jiangxi Vocational and Technical College of Information Application, Jiangxi, Nanchang, 330043 \\ 54892713@163.com
}

Keywords: B2C, Transactional Shop, User Experience, Decoration, Design

\begin{abstract}
With the advent and widely use of the Internet, research on trading shop has got more and more attention. The design quality of transactional shop is the key to the success of the transaction shop. Unlike other commodities-trading shop, the user will first experience the transaction shop design and usability before online transactions. In the Internet era, people visit transactional shop, the experience of appearance and the availability of transactional shop will attractive you and you can influence the degree of the deal shop preferences. Only a high degree of user preferences transactional shop, only attract more consumers online transactions, thereby accelerating the development of transactional shop.
\end{abstract}

\section{Introduction}

In the context of the rapid progress of information technology, e-commerce to develop and by the love of people around the world, its rich features and convenience to people's daily work and life has brought great convenience. B2C transactional online shop can provide a good market for buyers and sellers. The final identification of the site if the user experience is the basis of success in the process of satisfaction, only for a full understanding of user experience, the site will be able to draw lessons in the long-term development, and constantly improve their service.

With the popularity of Internet applications, transactional shop with its convenient, rapid development of the advantages of rich in the world and it has become a tremendous influence on the new business model. Shop accompanying transactional development matures, B2C (Business to Customer) such enterprises sell goods or services directly to consumers through a network mode transactional shop its amazing momentum occupy the major market-trading shop share. Seen in this light, B2C online shopping are being more and more people accept and use.

High-quality user experience is the basis for successful B2C-trading shop, shop class B2C transactions allow companies to win more customers resources in the fierce competition in the market, to ensure long-term healthy development of the site. And how to evaluate the user experience and gives the user a good experience, is a major problem faced by B2C-trading shop business, so shop for B2C transactions class user experience evaluation study is very necessary. This article as a starting point, by analyzing transactional B2C shop user experience elements and their evaluation, and build B2C transactional Shop decoration design element model, and finally put forward some suggestions to improve the transactional B2C shop user experience based on the analysis results in order to promote B2C transactional shop good development.

\section{The Overview of B2C Transactional Shop}

B2C transactional mode Shop was trading class on the Internet originated, is one of the most mature business model, which has a complete two-way communication channels, flexible trading means, efficient logistics and cost-effective mode of operation, has attracted wide attention in the industry. Although B2C transactional shop has achieved great success, but there are still many problems, such as users shop for B2C transactions class mistrust, poor product information viewed, the information so that users can not navigate successfully find the desired information, these problems give users a sense of bad shopping experience. The user experience is one of the key 
factors in transactional B2C shop operators, the website and service experience to give buyers have a decisive influence on the purchase decision.

\section{The Overview of User Experience}

User Experience refers to the user in the operation or use of a product or service we do, think, and feel. Many scholars of the user experience of many in-depth research. James Garrett user experience elements proposed five levels: the presentation layer, the frame layer, structural layer, scope and strategic levels, including the presentation layer including visual design, the framework layer includes interface design, navigation design and information design, structural layer including interaction design and information architecture, range layer including functional specifications and content needs, including user needs and strategic level website targets. In 2004, Robert Rubinoff proposed to quantify the user experience there are four important interrelated factors: brand, usability, functionality and content. Study and other elements of the site's information architecture, from information architecture, information design, workflow, resource conversion, compatible interface design and user experience across platforms and other elements of the microscopic aspects were analyzed. One problem is that the user experience is crucial to evaluate how the user experience. Some scholars believe from technical factors and man-machine interaction in non-technical factors to evaluate the user experience, technical factors such as system usefulness and ease of use, non-technical factors such as enjoyment, visual beauty and attract sexual content. Zeng Fan from the dimension of security, sexual content, visual style and interactive behavior of the user experience evaluation studied.

Through the above analysis, user experience factors are many, the shop is also true for B2C transactions category, the site user experience to conduct a comprehensive evaluation to objectively reflect the effect of the user experience. Therefore, building a system of comprehensive B2C transactional evaluation model shop user experience is necessary, but it is not the existence of such evaluation model. In this paper, starting from the user experience, we explore evaluation elements and indicators B2C transactional shop user experience and Evaluation Model Shop B2C transaction class user experience, formation evaluation method B2C transaction class user experience of a shop system.

\section{The Importance of Design and Decoration of B2C Transactions Shop}

With the wide application of the Internet, the rapid development of online shopping, online shopping user scale performance and rapid growth trend. How to attract users to browse and shop for a transactional subsequent actual operation, so online shopping transactions, increase trading volume, become Shop design transactional key.

User Experience transactional shop refers to all experience process users to browse or use a site from the perspective of user experience research site design, mainly focused on two issues, namely how to attract customers to the site up; the second is how to attract customers to use the site. After the user perception and actual use of transactional shop, how to scientifically evaluate the transaction class shop and targeted improvements in shop-trading problems that site to enhance the user's preference and loyalty to the site to use, has been become a huge challenge for transactional shop operators and researchers facing the user experience.

Most of the current research in this area from a usability point of view, website usability Jakob Nielsen research pioneer usability principles in his "Usability Engineering", a book discussed, has become the norm in many web designers follow; a Turner can be proposed Website Usability classification approach for researchers and designers to understand the degree of availability of the website provides a basis Usability too much attention to the design of the product itself, ignoring the user's emotional feelings and needs, and to make up for a good user experience The disadvantage of availability. More and more scholars began to focus on user reaction product design features cause. 
In summary, the present study evaluated the transaction type the shop's main website from a usability point of view to consider, not the availability of two aspects of the transaction from the user class network sites subjectively perceived attractiveness and experience from the practice site to site shop for a comprehensive evaluation study. This article is the user experience and usability theory based on the study, based on the relationship between the right to re-order determination method is proposed B2C transactional evaluation model shop user preference and availability from a site look attractive two angles, forming a system of qualitative and quantitative the combination of transactional Shop fitting design.

\section{Decoration and Design Elements of B2C Transactional Shop Based on User Experience}

Brand. Brand brings premium to $\mathrm{B} 2 \mathrm{C}$ transactions shop, the value of an intangible asset generates and the source of its value comes from the minds of consumers brand image formation. Shop class once a B2C transactions become strong brands in their field, it has the unique brand image, distinctive brand personality, wide popularity can bring high-quality user experience, while the brand's strength can make it have more loyal customers and continuously to bring value to B2C-trading shop. Visibility, recognition and attractiveness evaluation article from brand to brand shop class B2C transactions were measured.

Visual design. Visual design is the most direct perception of the user site, the visual perception of a direct impact on the user experience, so shop class B2C transactions should take it as a factor user experience. In this study, the visual design is mainly in the form of Products, including style layout and page color tone. Visual elements should be simple and elegant, easy to understand, to help users get a good online experience. Therefore, this article will aesthetics, clarity, friendliness and comfort as an evaluation index B2C transaction class visual design shop.

Interaction design. B2C online shopping is different from the traditional store shopping, customers can not see the goods in kind, cannot face to face communication and sellers, which gives customers understand the products bring great obstacles, so to provide the appropriate interactive channel will need a website. Good customer interaction can deepen understanding of the goods, so that customers can decide quickly whether to buy goods. Interaction throughout the shopping process and it is an important factor in the user experience. The article from the efficiency, fluency and legibility other aspects of the B2C transactional interaction design Shop measured.

Shopping process. When the user needs to be a series of operations on B2C transactions class shopping shop, since the user directly involved in these processes, so the shopping process for granted as B2C transactions should shop class user experience one of the elements. B2C transactional shop shopping process is basically the same, including seven areas: Register - buy order - choose shipping method - Payment - Shopping completion - Orders query. Shop class B2C transactions need to ensure that the entire process easy to operate, easy to use, and the user can return, cancel the previous operation. Therefore, this article will be convenience, simplicity and reversibility as an evaluation index shopping process.

Information architecture. Information architecture, namely Information Architecture, was first proposed in 1975 by the American architect Richard Saul, he pointed out that IA is the construction of the information structure. IA since made it is mainly used in the construction site. Peter and Louis Rosenfeld book Information Architecture for the World Wide Web a book first proposed site information architecture of the four components: organizational system, marking system, navigation and retrieval systems. Shop class B2C transactions is the basic framework constituted by these four systems, so the user experience online shop class B2C transactions need to build four systems begin to analyze the elements from the information. This article from the organization rationality, normative identity, logo consistency, ease of search and navigation accuracy and other aspects of the B2C transactional information online shop build evaluated.

Security. Security is the foundation of transactional shop. Shop class B2C transactions need to provide good security mechanism to ensure that users do not have concerns about the transaction process, can rest assured shopping and it gives the user a safe and reliable experience. This article 
from the system stability, transaction availability, payment security, reliability and user rights protection and other security evaluation of B2C transactions were measured shop class.

Personalized service. Personalized service is an important part of the service design, under the network environment is also reflected in the service key value lies. For B2C online shopping, different users have different needs, in order to get the best service value, B2C transaction class shop need to give different groups provide different services. Personalized service form the major commodities B2C website recommended site based on user's registration information, purchase history, search history, etc. can roughly determine the user's shopping preferences, and then through the mail, online reminders according to user preferences, the personal home page of commodity push, and Product recommendation between users to provide personalized service. This article accuracy, transparency, diversification and controllability as an evaluation index personalized service.

\section{Conclusion}

The user experience evaluation dimensions and indicators of $\mathrm{B} 2 \mathrm{C}$ transactional shop are important for transactional B2C shop design and improvement, the designer from the brand, visual design, interactive feedback, information architecture, security and personalized service aspect to grasp the user's preference, design a more attractive trading class shop, developed to attract users, retain customers and maintain customer loyalty strategies.

\section{References}

[1] R.X. Zeng, Discussion about Website Usability Study, Tianjin Vocational and Technical Normal College, 5(2007) 46-47.

[2] C.Li, Understanding of web usability and its principles, Computer Age. 11(2006) 26-30.

[3] C.Y.Wang, The availability of e-commerce site, Market Modernization. 9 (2011) 56-58.

[4] J.X.Li, Business website interface usability design, Market Modernization .9(2009) 19-22.

[5] Y.X.Zhang, Discussion about the availability of e-commerce sites, E-commerce. 4(2007) 129-132. 